\title{
Genotyping and characterization of prophage patterns in clinical isolates of Staphylococcus aureus
}

Mahya Dini ${ }^{1}$, Leili Shokoohizadeh ${ }^{1}$, Farid Aziz Jalilian², Abbas Moradi ${ }^{3}$ and Mohammad Reza Arabestani ${ }^{1} 4^{*}$

\begin{abstract}
Objective: Staphylococcus aureus is considered an important pathogen with a variety of virulence factors in communities and hospitals all around the world. Prophage typing is a practical technique for categorizing this bacterium. In this study, we focused on the detection of prophage patterns in methicillin-resistant S. aureus (MRSA) and methicillinsensitive S. aureus (MSSA) strains based on their virulence factors, antimicrobial resistance patterns, and molecular typing by rep-PCR.

Results: Out of 126 S. aureus isolates, 45 (35.7\%) were identified as MRSA. In total, 17 different prophage types were detected and 112 strains out of 126 strains contained at least one prophage. There was a statistically significant relationship between $h / d$, $h / g$, eta and SGA, SGA, and SGFb, respectively. The results of the rep-PCR analysis revealed 14 different patterns among the MRSA and MSSA isolates. In conclusion, the presence of different prophage-encoded virulence factors and antibiotic-resistant genes among MRSA strains enables them to produce a broad range of diseases. Thus, diverse MRSA strains which have these prophages can be considered as a potential threat to the patient's health in either the hospital or the community.
\end{abstract}

Keywords: Methicillin-resistant Staphylococcus aureus, Virulence factors, Prophage patterns, rep-PCR

\section{Introduction}

Staphylococcus aureus is a gram-positive coccus and is considered a normal flora or an opportunistic pathogen which can cause community-acquired (CA) and hospitalacquired (HA) infections. S. aureus can cause a different range of diseases from soft tissue and skin infections to severe life-threatening infections such as toxic shock syndrome (types 1 and 2)[1,2]. The capability of producing different virulence factors is the main reason for the high pathogenicity of $S$. aureus. In addition to its high pathogenicity, this bacterium also has high adaptive powers against environmental changes [3, 4]. Bacteriophages can convert non-pathogenic strains to pathogenic strains through the horizontal transduction of the virulence gene [5].

\footnotetext{
*Correspondence: Mohammad.arabestani@gmail.com

1 Department of Microbiology, Faculty of Medicine, School of Medicine, University of Hamadan, Hamadan, Iran

Full list of author information is available at the end of the article
}

The production of virulence factors is the result of the phenotypic changes caused by lysogenic conversion which plays an important role in the biology of these species [6-11]. S. aureus phages that are involved in human diseases are classified into six categories: 3 SGA, 11 SGB, 77 SGF (with the two subgroups SGFa and SGFb) and 187 SGL which belong to the siphoviridae family, while SGD or the Twort-like phage belongs to the myoviridae family [2].

In recent years, in epidemiological studies and in assessing the genetic linkages of bacteria, common methods of bacterial typing have been replaced by molecular methods [12]. The rep-PCR technique is an alternative technique for producing fingerprint directly and without using endonuclease enzymes. Staphylococcal bacteriophages are widely used in the typing of Staphylococcus strains associated with human diseases through the rep-PCR technique [13-15]. Given that there are few studies about investigating the relationship between different prophage patterns, virulence factors, 
antibiotic resistance, $\mathrm{SCCmec}$, and rep types in Iran and some other countries, the current study focuses on this field.

\section{Main text \\ Methods \\ Sampling and isolation of S. aureus}

A total of 126 samples isolated in a previous study by Tahmasebi et al. were used [16]. This study was approved by the ethics committee of Hamadan University of Medical Sciences (No: IRUMSHA. REC. 1397.193).

\section{Antibiotic susceptibility testing}

For all the $S$. aureus isolates, antibiotic susceptibility testing was done using Kirby-Bauer disk diffusion method according to Clinical and Laboratory Standard Institute (2016) guidelines. The antibiotic disks (Mast, UK) used in this study included cefoxitin $(30 \mu \mathrm{g})$, tetracycline $(10 \mu \mathrm{g})$, penicillin $(10 \mathrm{u})$, erythromycin $(15 \mu \mathrm{g})$, vancomycin $(30 \mu \mathrm{g})$, cefazolin $(10 \mu \mathrm{g})$, and ciprofloxacin $(5 \mu \mathrm{g})$. Methicillin-resistance was detected using a cefoxitin disk and a cefoxitin E-test (Italy, Liofilchem). S. aureus ATCC43300 and $S$. aureus ATCC25923 were used as positive and negative controls, respectively.

\section{DNA extraction}

The total genomic DNAs of the isolates were extracted by the boiling method. The quality of the extracted DNAs was assessed using a Nanodrop device (A \& E Lab Nano200, UK).

\section{Detection of virulence factors}

Hemolysin genes ( $h l a, h l b, h l c$, and $h l d)$, exfoliative toxins (et $\mathrm{A}$, et $\mathrm{B}$, and et $\mathrm{d})$, Panton-Valentine leukocidin (PVL) genes ( $p v l 1, p v l 2$, and $p v l 3)$, toxic shock syndrome toxin (tsst) and $S$. aureus enterotoxin (seA) genes were identified using the PCR assay as described in our previous studies $[16,17]$.

\section{Detecting the prophages of S. aureus}

Multiplex PCR assay was used for identifying SGA, SGB, SGD, SGL, and SGF (and its two subgroups SGFa and $\mathrm{SGFb}$ ) genes by their particular primers. The primers used for $S$. aureus bacteriophages are given in Additional file 1: Table S1. The PCR protocol used was based on the study of Pantuck et al. [1].

\section{Detection of SCCmec types}

$\mathrm{SCCmec}$ types I to $\mathrm{V}$ were detected using a multiplexPCR assay reported previously [9].

\section{Sequencing}

One sample of each prophage PCR product (amplicon) was sequenced by Bioneer Co. (South Korea) and the data were analyzed using the Chromas software.

\section{Rep-PCR}

Rep-PCR was performed on 55 isolates chosen from the MRSA and MSSA strains based on their prophage profiles using the primers indicated in (Additional file 1: Table S1).

\section{Analysis of the rep-PCR results}

The rep-PCR band patterns were compared and clustered by Dice and unweighted paired group (UPGMA) methods using an online service (the inslico.ehu.es database), respectively.

\section{Statistical analysis}

The data were analyzed using SPSS software version 16 (Chicago, SPSS Inc., IBM, USA). Descriptive statistical methods were used to determine the frequency, percentage, and mean, while Fisher's test was used to compare the qualitative results. $\mathrm{P} \leq 0.05$ was considered as statistically significant.

\section{Results}

Prevalence of MRSA strains

Among 126 tested S. aureus isolates, 45 strains (35.7\%) showed resistance to cefoxitin and were identified as MRSA isolates. All the MRSA isolates carried the mecA gene.

\section{SCCmec typing}

The results of the SCCmec typing of MRSA strains revealed that these strains were positive for SCCmec types I (4\%), II (12.7\%), III (9.5\%) and were classified as hospital-acquired MRSA strains. Furthermore, (15.9\%), (2.4\%), (4\%), and (4\%) of the MRSA strains which harbored SCCmec types IVa, IVb, IVc, and IVd, respectively, were considered as community-acquired MRSA (Table 1).

\section{Prevalence of virulence factors}

The prevalence of the virulence factors is given in Additional file 2: Figure S1. The hla gene was the prevalent virulence factor $(12.7 \%)$ and $p v l 1, p v l 2$, and sea showed the least (7.9\%) distribution among the $S$. aureus isolates.

\section{Prevalence of prophages}

The results of this study showed that out of 126 strains, 112 contained at least one prophage (Additional file 3: Figure S2). SGB (88\%) was the most prevalent prophage, while SGL and SGA were the least prevalent prophages 
Table 1 Prevalence of antibiotic resistance genes among the $S$. aureus isolates

\begin{tabular}{|c|c|c|c|c|}
\hline & Primer sequence $5^{\prime} \rightarrow 3^{\prime}$ & $\begin{array}{l}\text { PCR product length } \\
\text { (bp) }\end{array}$ & Primer position & References \\
\hline SGA1 SGA2 & $\begin{array}{l}\text { TATCAGGCGAGAATTAAGGG } \\
\text { CTTTGACATGACATCCGCTTGAC }\end{array}$ & 744 & $\begin{array}{l}1409-1428 \\
2152-2130\end{array}$ & {$[1]$} \\
\hline SGB1 SGB2 & $\begin{array}{l}\text { ACTTATCCAGGTGGYGTTATTG } \\
\text { TGTATTTAATTTCGCCGTTAGTG }\end{array}$ & 405 & $\begin{array}{l}1639-1660 \\
2043-2021\end{array}$ & [1] \\
\hline SGF1 SGF2 & $\begin{array}{l}\text { CGATGGACGGCTACACAGA } \\
\text { TTGTTCAGAAACTTCCCAACCTG }\end{array}$ & 155 & $\begin{array}{l}515-553 \\
669-647\end{array}$ & [1] \\
\hline SGFa1 SGFa2 & $\begin{array}{l}\text { TACGGGAAAATATTCGGAAG } \\
\text { ATAATCCGCACCTCATTCCT }\end{array}$ & 548 & $\begin{array}{l}2487-2506 \\
3034-3015\end{array}$ & {$[1]$} \\
\hline SGFb1 SGFb2 & $\begin{array}{l}\text { AGACACATTAAGTCGCACGATAG } \\
\text { TCTTCTCTGGCACGGTCTCTT }\end{array}$ & 147 & $\begin{array}{l}20013-20035 \\
20159-20139\end{array}$ & {$[1]$} \\
\hline $\begin{array}{l}\text { SGL1 } \\
\text { SGL2 }\end{array}$ & $\begin{array}{l}\text { GCTTAAAACAGTAACGGTGACAGTG } \\
\text { TGCTACATCATCAAGAACACCTGG }\end{array}$ & 548 & $\begin{array}{l}2263-2287 \\
2911-2888\end{array}$ & {$[1]$} \\
\hline $\begin{array}{l}\text { SGD1 } \\
\text { SGD2 }\end{array}$ & $\begin{array}{l}\text { TGGGCTTCATTCTACGGTGA } \\
\text { GTAATTTAATGAATCCACGAGAT }\end{array}$ & 331 & $\begin{array}{l}781-800 \\
1111-1089\end{array}$ & [1] \\
\hline REP1 REP 2 & IIIICGICGICATCIGGC ICGICTTATCIGGCCTAC & Variable & & [18] \\
\hline
\end{tabular}

Table 2 Prophage patterns of S. aureus isolates

\begin{tabular}{lcc}
\hline Resistance gene & Negative & Positive \\
\hline mecA & $81(64 / 3)$ & $45(35 / 7)$ \\
mecR & $114(90 / 5)$ & $12(9 / 5)$ \\
mecl & $121(96)$ & $5(4)$ \\
ccra.a4 & $106(84 / 1)$ & $20(15 / 9)$ \\
ccra.b3 & $112(88 / 9)$ & $14(11 / 1)$ \\
ccra.b2 & $103(81 / 7)$ & $23(18 / 3)$ \\
ccra.b1 & $110(92 / 1)$ & $16(7 / 9)$ \\
ccar2.b & $121(96)$ & $5(4)$ \\
sCCmecl & $116(92 / 1)$ & $10(7 / 9)$ \\
sCCmecll & $110(87 / 3)$ & $16(12 / 7)$ \\
sCCmeclll & $114(90 / 5)$ & $12(9 / 5)$ \\
sCCmecIVa & $20(15 / 9)$ \\
sCCmecIVb & $106(84 / 1)$ & $3(2 / 4)$ \\
sCCMECIVC & $123(97 / 6)$ & $5(4)$ \\
sCCmecIVd & $121(96)$ & $5(4)$ \\
ccrC & $121(96)$ & $9(7 / 1)$ \\
ermA & $117(92 / 9)$ & $5(4)$ \\
ermB & $121(96)$ & $9(7 / 1)$ \\
ermC & $117(92 / 9)$ & $14(11 / 1)$ \\
BlaZ & $112(88 / 9)$ & $126(100)$ \\
\hline
\end{tabular}

(3.2\%). All of the phage types were detected in the MRSA and MSSA strains, except for SGL which was detected only in the MRSA strains. In total, 17 different prophage types were detected among the $S$. aureus isolates in this study (Table 2).

\section{The relationship between prophages and virulence factors}

By using Fisher's test, it was noticed that the P. values of $h l d / \mathrm{SGA}, h l g / \mathrm{SGA}$, and eta/SGFb were 0.05, 0.04, and
0.04, respectively. This shows that there is a statistically significant relationship between these virulence factors and their related prophages.

\section{The relationship between prophages and SCCmec types}

The comparison of the antibiotic resistance genes and the presence of prophages showed that there was a statistically significant relationship between: SGB and mecA; $\mathrm{SGFa}$ and $m e c \mathrm{~A}, m e c \mathrm{R}$, and mecC; $\mathrm{SGFb}$ and $m e c \mathrm{~A}$ and SCCmec IV; SGL and mecR and SCCmec IVa; and SGF and mecA (Table 3).

\section{The results of rep-PCR}

The analysis of genetic linkage among the isolates using rep-PCR showed a similarity of $50-100 \%$ among the S. aureus isolates (Additional file 4: Figure S3). Genetic diversity was established among the $S$. aureus isolates by detecting 14 different rep-PCR fingerprints with the similarity cutoff of $\geq 95 \%$. Fourteen different rep-PCR profiles, including seven common types and seven unique types, were identified.

\section{Discussion}

In the present study, the frequency of resistance to methicillin was $35.7 \%$. Most studies in Iran have reported the prevalence of MRSA from 43 to $56 \%[19,20]$. However, the rate of MRSA in our study is lower than those of some studies in Iran and other countries.

Our findings revealed that all the prophage types (SGA, SGB, SGD, SGF, SGFa, SGFb, and SGL) were detected among the MRSA and MSSA strains and the SGB prophage type was the predominant one. However, SGF prophage has been the predominant prophage type in previous reports from 2012 to 2018 in Iran [2, 19-22]. 
Table 3 The relationship between prophages and antimicrobial resistance genes based on the $P$ values

\begin{tabular}{|c|c|c|c|c|c|c|c|c|}
\hline \multirow[t]{2}{*}{ Phage pattern } & \multicolumn{7}{|c|}{ Pahe type } & \multirow[t]{2}{*}{ No (\%) } \\
\hline & SGB & SGD & SGFa & SGFb & SGA & SGF & SGL & \\
\hline Pattern 1 & - & - & + & + & - & - & - & 12 \\
\hline Pattern 2 & - & + & + & - & - & + & - & 3 \\
\hline Pattern 3 & - & + & + & - & - & - & - & 7 \\
\hline Pattern 4 & + & - & + & + & - & - & - & 2 \\
\hline Patten 5 & - & - & + & + & - & + & - & 9 \\
\hline Pattern 6 & - & - & + & - & - & + & - & 48 \\
\hline Pattern 7 & - & - & - & + & - & + & - & 13 \\
\hline Pattern 8 & - & - & + & - & + & + & - & 3 \\
\hline Pattern 9 & + & - & + & - & - & + & - & 14 \\
\hline Pattern 10 & + & - & - & - & - & - & + & 2 \\
\hline Pattern 11 & + & - & - & + & - & + & - & 6 \\
\hline Pattern 12 & - & + & - & - & - & + & + & 1 \\
\hline Pattern 13 & - & + & + & - & - & - & - & 1 \\
\hline Pattern 14 & - & + & - & - & - & - & + & 1 \\
\hline Pattern 15 & + & + & - & - & - & - & + & 1 \\
\hline Pattern 16 & - & + & - & - & - & - & - & 2 \\
\hline Pattern 17 & - & - & - & - & - & - & + & 1 \\
\hline
\end{tabular}

In the current study, the SGD prophage was also detected among the S. aureus strains. Rahimi et al. reported four different prophage patterns and six different prophage types among the MRSA strains isolated from Tehran hospitals in Iran $[20,23]$. However, in our study, seventeen different prophage patterns and seven different prophage types were detected. In contrast to a previous study in Iran in which the prophage pattern SGB/SGF/GFa/SGFb $(81 \%)$ was reported as the dominant pattern, in the current study, SGF/SGFa was identified as the dominant pattern in $38 \%$ of the isolates [22].

Another difference between the findings of the present research and those of other researches in Iran is that SGL was found among the studied strains of this study while it was not reported in previous studies.

According to the results of the current study, there was not a significant relationship between resistance to methicillin and prophage types. All prophage types were detected among both MRSA and MSSA strains except for SGL which was detected only among the MRSA isolates. In the present study, the hla gene detected in $12 \%$ of the strains was the predominant hemolysin gene. The $h l b$ gene detected in $11 \%$ of the $S$. aureus strains was the second dominant hemolysin gene, though it was the predominant hemolysin gene and was detected in 100\% of the MRSA strains in a study by Rahimi et al. in Tehran hospitals in 2018 [23]. According to the results of the current study, both MRSA and MSSA strains had the hla gene, however, the prevalence of this gene was significantly more in the MRSA strains which proves the relationship between this virulence factor and methicillin resistance in $S$. aureus. On the other hand, there was a statistically significant relationship between SGA and hld which is another hemolysin gene.

Another statistically significant relationship between prophages and virulence factors was the one between eta and SGFb. In contrast to Rahimi et al. [23] who showed that there was a relationship between eta and SGB, the authors of the current study did not find the same result. In the current study, the frequency of sea, hemolysin, and tst genes was lower than those of other studies in Iran and other countries [19,24-26]. One of the reasons for the low abundance of these genes may be the low number of samples tested in this study compared to those of similar studies. However, the frequency of $p v l$ genes was a little higher than those of other studies in Iran. PVL is one of the most important virulence factors and a marker for SCCmec type II which is associated with SGA phages $[2,27]$. In the current study, $p v l$ genes were found among strains with SCCmec (types I, II, III, IV), and SGF, SGD, and SGB phages. This shows the community origins of these strains because the presence of the $p v l$ gene is only limited to CA-MRSA strains. According to the PCR results, 28 out of $126(22.22 \%)$ S. aureus isolates were pvl carriers. In 2013, Abimanyu et al. in India reported that 10 out of 25 (40\%) MRSA isolates were positive for $p v l$ genes [28] which was higher than the results of our study. In another study in Iran, Ohadian Moghadam et al. 
showed that $14.3 \%$ of the 56 isolated S. aureus collected from Isfahan were PVL-positive [29].

In the current study, SCCmec I, II, III were detected among the HA-MRSA strains and SCCmec IVa, IVb, IVc, IVd were found among the CA-MRSA strains. Consistent with previous studies in Iran and in most Asian countries, SCCmec type III was found as the dominant SCCmec type among the HA-MRSA isolates [19, 30, 31]. In the current study, SCCmec IVa showed a higher frequency among the SCCmec types. This type was reported by Edselve et al. in Denmark. In the current study, SCCmec type $\mathrm{V}$ was detected in none of the isolates.

In the current study, S. aureus isolates were categorized by SCCmec typing, phage typing, and rep-PCR. In the study of Sommerhalter et al. it has been shown that the performance of rep-PCR typing is comparable to those of other typing methods. The analysis of the linkage among the isolates by rep-PCR showed a genetic diversity among the $S$. aureus isolates (14 different rep-PCR profiles including seven common types and seven unique types). The common types including A and G harbored 10 and 14 isolates, respectively. Isolates in the same rep profiles showed different phage patterns, virulence genes, SCCmec types, and $p v l$ genes. Therefore, it can be concluded that there is no significant relationship between the rep patterns and the phage profiles, virulence genes, and SCCmec types. The results of studies from Iran and other countries indicated diversity among MRSA isolates from hospitals and the community. In a study by Manafi et al. in Iran [32], six main clusters of S. aureus were detected by rep-PCR and no significant relationship was observed between PVL-positive S. aureus and rep-PCR patterns. This is in line with our findings.

\section{Conclusion}

Our findings illustrated the high diversity of different prophage types, rep types, and SCCmec types in both MRSA and MSSA strains. According to the results of the rep-PCR technique, we also face diverse $S$. aureus isolates in hospitals in Hamedan and their circulation from the community to the hospitals and vice versa.

\section{Limitation}

The results of this study had some similarities and discrepancies with those of other studies. It is necessary to conduct studies with more samples in different areas and to use robust typing methods to obtain better results for better interpretations.

\section{Supplementary information}

Supplementary information accompanies this paper at https://doi. org/10.1186/s13104-019-4711-4.
Additional file 1: Table S1. Primer sequences used in the prophage typing and rep-PCR in the $S$. aureus isolates.

Additional file 2: Figure S1. Prevalence of virulence factors among 126 clinical isolates of $S$. aureus.

Additional file 3: Figure S2. Prevalence of prophage types among 126 clinical isolates of $S$. aureus

Additional file 4: Figure S3. The dendrogram of rep-PCR analysis for 55 clinical isolates of S. aureus. The common types are marked.

\section{Abbreviations}

MRSA: Methicillin-resistant Staphylococcus aureus; MSSA: Methicillin-sensitive Staphylococcus aureus; HGT: horizontal gene transfer; PVL: Panton-Valentine leukocidin; sea: enterotoxin gene; tst: toxic shock toxin.

\section{Acknowledgements}

The authors of this article are grateful to Hamadan University of Medical Sciences for their financial support for conducting the research. This work was supported by the Research and Technology Vice-Chancellor of Hamadan University of Medical Sciences (grant number: 9703291715).

\section{Authors' contributions}

MD performed the tests and collected and analyzed the data. LSH and FAJ advised and contributed to writing and editing the manuscript. AM performed the analysis of the data. MRA designed the project and contributed to the whole steps of the project. All authors read and approved the final manuscript.

\section{Funding}

The Research and Technology Vice-Chancellor of Hamadan University of Medical Sciences funded this research (Project Number: 9703291715). The role of the funding was to supply the acquisition of the necessary materials for the research. There isn't any funding in the design of the study and collection, analysis, and interpretation of data and in writing the manuscript.

\section{Availability of supporting data}

The supporting data files include Additional file 1: Table S1 and Additional file 2: Figures S1, Additional file 3: Figures S2, Additional file 4: Figures S3.

\section{Ethical approval and consent to participate}

This study was approved by the ethics committee of Hamadan University of Medical Sciences (No: IRUMSHA. REC. 1397.193). Consent to participate is not applicable.

\section{Consent for publication}

Consent for publication is not applicable for this study.

\section{Competing interests}

The authors declare that they have no competing interests.

\section{Author details}

${ }^{1}$ Department of Microbiology, Faculty of Medicine, School of Medicine, University of Hamadan, Hamadan, Iran. ${ }^{2}$ Department of Virology, School of Medicine, University of Hamadan, Hamadan, Iran. ${ }^{3}$ Department of Community Medicine, Hamadan University of Medical Sciences, Hamadan, Iran.

${ }^{4}$ Nutritious Research Center, Hamadan University of Medical Sciences,

Hamadan, Iran.

Received: 26 August 2019 Accepted: 3 October 2019

Published online: 21 October 2019

\section{References}

1. Pantůček R, Doškař J, Rủžičková V, Kašpárek P, Oráčová E, Kvardova V, et al. Identification of bacteriophage types and their carriage in Staphylococcus aureus. Adv Virol. 2004;149(9):1689-703. 
2. Rahimi F, Bouzari M, Katouli M, Pourshafie MR. Prophage and antibiotic resistance profiles of methicillin-resistant Staphylococcus aureus strains in Iran. Adv Virol. 2012;157(9):1807-11.

3. Gill SR, Fouts DE, Archer GL, Mongodin EF, DeBoy RT, Ravel J, et al. Insights on evolution of virulence and resistance from the complete genome analysis of an early methicillin-resistant Staphylococcus aureus strain and a biofilm-producing methicillin-resistant Staphylococcus epidermidis strain. J Bacteriol. 2005;187(7):2426-38.

4. Gordon RJ, Lowy FD. Pathogenesis of Methicillin-Resistant Staphylococcus aureus Infection. Clin Infect Dis. 2008;46(1):S350-9.

5. Wilson BA, Salyers AA. Is the evolution of bacterial pathogens an out-ofbody experience? Trends Microbiol. 2003;11 (8):347-50.

6. Baba T, Takeuchi F, Kuroda M, Yuzawa H, Aoki K-I, Oguchi A, et al. Genome and virulence determinants of high virulence community-acquired MRSA. Lancet. 2002;359(9320):1819-27.

7. Betley MJ, Mekalanos JJ. Staphylococcal enterotoxin A is encoded by phage. Science. 1985;229(4709):185-7.

8. Carroll D, Kehoe MA, Cavanagh D, Coleman DC. Novel organization of the site-specific integration and excision recombination functions of the Staphylococcus aureus serotype F virulence-converting phages $\varphi 13$ and 442. Mol Microbiol. 1995;16(5):877-93.

9. Colman DC, Sullivan DJ, Russel RJ, Arbuthnott JP, Carey BF, Pomeroy HM. Staphylococcus aureus bacteriophages mediating the simultaneous lysogenic conversion of $\beta$-lysin, staphylokinase and enterotoxin A: molecular mechanism of triple conversion. Microbiology. 1989;135(6):1679-97.

10. Kuroda M, Ohta T, Uchiyama I, Baba T, Yuzawa H, Kobayashi I, et al. Whole genome sequencing of meticillin-resistant Staphylococcus aureus. Lancet. 2001;357(9264):1225-40.

11. Lee CY, landolo JJ. Mechanism of bacteriophage conversion of lipase activity in Staphylococcus aureus. J Bacteriol. 1985;164(1):288-93.

12. Van Belkum A, Tassios P, Dijkshoorn L, Haeggman S, Cookson B, Fry N, et al. Guidelines for the validation and application of typing methods for use in bacterial epidemiology. Clin Microbiol Infect. 2007;13:1-46.

13. Blair J, Williams R. Phage typing of staphylococci. Bull World Health Organ. 1961;24(6):771.

14. Richardson J, RosdahI V, Van Leeuwen W, Vickery A, Vindel A, Witte W. Phages for methicillin-resistant Staphylococcus aureus: an international trial. Epidemiol Infect. 1999;122(2):227-33.

15. Wentworth BB. Bacteriophage typing of the staphylococci. Bacteriol Rev. 1963;27(3):253

16. Tahmasebi H, Dehbashi S, Arabestani M. Resistance pattern to macrolides and tetracyclines and detection of ermA, ermB, emrC and mphc genes in clinical isolates of Staphylococcus aureus producing toxic shock syndrome toxin-1. Koomesh. 2019;21(1):188-94.

17. Motamedi H, Asghari B, Tahmasebi H, Arabestani MR. Identification of hemolysine genes and their association with antimicrobial resistance pattern among clinical isolates of Staphylococcus aureus in West of Iran. Adv Biomed Res. 2018;7:153

18. Sorkh MAG, Shokoohizadeh L, Rashidi N, Tajbakhsh E. Molecular analysis of Pseudomonas aeruginosa strains isolated from burn patients by repetitive extragenic palindromic-PCR (rep-PCR). Iran Red Crescent Med J. 2017. https://doi.org/10.5812/ircmj.43508.

19. Rahimi F, Karimi S. Characteristics of virulence factors in methicillinresistant staphylococcus aureus strains isolated from a referral hospital in Tehran, Iran. Arch Clin Infect Dis. 2016. https://doi.org/10.5812/archc id.33220.

20. Rahimi F, Bouzari M, Katouli M, Pourshafie M. Prophage typing of methicillin resistant Staphylococcus aureus isolated from a tertiary care hospital in Tehran, Iran. Jundishapur J Microbiol. 2012;6(1):80-5.

21. Rahimi F, Katouli M, Pourshafie MR. Characteristics of hospital-and community-acquired meticillin-resistant Staphylococcus aureus in Tehran, Iran. J Med Microbiol. 2014;63(6):796-804. https://doi.org/10.1099/ jmm.0.070722-0.

22. Rahimi F, Karimi S. Isolation of methicillin-resistant Staphylococcus aureus strains producing enterotoxins A, K and Q From chicken meat in Isfahan, Iran, 2014. Arch Clin Infect Dis. 2016;11(4):e35601.

23. Rahimi F, Shokoohizadeh L. Characterization of virulence factors and prophage profiles of methicillin-resistant Staphylococcus aureus strains isolated from a referral hospital in Tehran, Iran. Arch Clin Infect Dis. 2018;13(5):e59385. https://doi.org/10.5812/archcid.59385.

24. Asadollahi P, Delpisheh A, Maleki MH, Jalilian FA, Alikhani MY, Asadollahi K, et al. Enterotoxin and exfoliative toxin genes among methicillin-resistant Staphylococcus aureus isolates recovered from Ilam, Iran. Avicenna J Clin Microbiol Infect. 2014;1(2):e20208.

25. Klotz M, Opper S, Heeg K, Zimmermann S. Detection of Staphylococcus aureus enterotoxins A to D by real-time fluorescence PCR assay. J Clin Microbiol. 2003;41(10):4683-7.

26. Pourmand MR, Memariani M, Hoseini M, Yazdchi SB. High prevalence of sea gene among clinical isolates of Staphylococcus aureus in Tehran. Acta Med Iran. 2009;47:357-61.

27. Deurenberg RH, Stobberingh EE. The evolution of Staphylococcus aureus. Infect Genet Evol. 2008;8(6):747-63.

28. Abimanyu N, Krishnan A, Murugesan S. Use of triplex PCR for rapid detection of PVL and differentiation of MRSA from methicillin resistant coagulase negative staphylococci. J Clin Diagn Res JCDR. 2013:7(2):215.

29. Ohadian-Moghadam S, Havaei S, Pourmand M. Prevalence of methicillinresistant Staphylococcus aureus carrying panton-valentine leukocidin gene in cutaneous infections in the city of Isfahan. J Med Bacteriol. 2012:1(1-2):9-16.

30. Fasihi Y, Kiaei S, Kalantar-Neyestanaki D. Characterization of SCCmec and spa types of methicillin-resistant Staphylococcus aureus isolates from health-care and community-acquired infections in Kerman, Iran. J Epidemiol Glob Health. 2017;7(4):263-7.

31. Moosavian M, Shahin M, Navidifar T, Torabipour M. Typing of staphylococcal cassette chromosome mec encoding methicillin resistance in Staphylococcus aureus isolates in Ahvaz, Iran. N Microb N Infect. 2018:21:90-4.

32. Manafi A, Khodabandehloo M, Rouhi S, Ramazanzadeh R, Shahbazi B, Narenji H. Molecular epidemiology survey of Staphylococcus aureus Panton-Valentine Leukocidin-positive isolated from Sanandaj, Iran. Adv Biomed Res. 2017;6:87.

\section{Publisher's Note}

Springer Nature remains neutral with regard to jurisdictional claims in published maps and institutional affiliations.

Ready to submit your research? Choose BMC and benefit from

- fast, convenient online submission

- thorough peer review by experienced researchers in your field

- rapid publication on acceptance

- support for research data, including large and complex data types

- gold Open Access which fosters wider collaboration and increased citations

- maximum visibility for your research: over 100M website views per year

At $\mathrm{BMC}$, research is always in progress.

Learn more biomedcentral.com/submissions 